TI 2011-031/1

Tinbergen Institute Discussion Paper

\title{
Understanding Contract Audits: An Experimental Approach
}

Robert M.M. Bertrand 1,2

Arthur J.H.C. Schram 3,4

Eddy H.J. Vaassen ${ }^{2,5}$

' Ministry of Defense, the Netherlands;

2 School of Business and Economics, Maastricht University,

${ }^{3}$ Amsterdam School of Economics, University of Amsterdam;

${ }^{4}$ CREED, and Tinbergen Institute;

${ }^{5}$ Amsterdam Business School, University of Amsterdam. 
Tinbergen Institute is the graduate school and research institute in economics of Erasmus University Rotterdam, the University of Amsterdam and VU University Amsterdam.

More TI discussion papers can be downloaded at http://www.tinbergen.nl

Tinbergen Institute has two locations:

Tinbergen Institute Amsterdam

Gustav Mahlerplein 117

1082 MS Amsterdam

The Netherlands

Tel.: +31(0)205251600

Tinbergen Institute Rotterdam

Burg. Oudlaan 50

3062 PA Rotterdam

The Netherlands

Tel.: +31(0)10 4088900

Fax: +31(0)104089031

Duisenberg school of finance is a collaboration of the Dutch financial sector and universities, with the ambition to support innovative research and offer top quality academic education in core areas of finance.

DSF research papers can be downloaded at: http://www.dsf.nl/

Duisenberg school of finance

Gustav Mahlerplein 117

1082 MS Amsterdam

The Netherlands

Tel.: +31(0)20 5258579 


\title{
Understanding Contract Audits: An Experimental Approach
}

\author{
Robert M.M. Bertrand* \\ Arthur J.H.C. Schram ${ }^{+}$ \\ Eddy H.J. Vaassen ${ }^{\#}$
}

January 2011

\begin{abstract}
Contract audits aimed at reducing information asymmetry and transaction costs are frequently used in imperfect markets such as defense procurement. This contradicts predictions from standard economic theory. We conduct a laboratory experiment to investigate this paradox. Our laboratory setup allows us to investigate the conditions under which individuals decide to initiate a contract audit and to carefully assess its economic value. Our theoretical approach draws upon two distinct literatures. The theory of planned behaviour explains why organizations may engage in contract auditing even when markets are imperfect. Social preference theory explains why traders may adjust prices when a contract audit indicates that the original price yields an inequitable distribution of the surplus. Our results indeed show that audits lead to an increased share of the surplus for the buyer, but this increased welfare is completely offset by the audit costs. To further investigate motivations to initiate contract audits, we measure our subjects' attitudes towards contract auditing and their level of perceived behavioral control; and we manipulate subjective norms about having contract audits done. These treatments show that a positive attitude toward contract auditing, enhanced perceived behavioral control, and pressure to perform a contract audit all lead to more contract audits.
\end{abstract}

Key words: contract auditing, experimental economics, value of the audit

* Contact author: Ministry of Defense, the Netherlands, and School of Business and Economics, Maastricht University, the Netherlands; r.bertrand@maastrichtuniversity.nl.

${ }^{+}$CREED, Amsterdam School of Economics, University of Amsterdam, the Netherlands; a.j.h.c.schram@uva.nl.

${ }^{*}$ School of Business and Economics, Maastricht University, the Netherlands, and Amsterdam Business School, University of Amsterdam, the Netherlands: e.h.j.vaassen@uva.nl. 


\section{Introduction}

When a nation's Ministry of Defense is out to buy new fighter jets, it generally does not have many options to choose from. Usually it has to do so in a market where only a single or few suppliers are active. This lack of competition raises obvious problems of pricing that many government institutions will want to avoid. To deal with this, contract audits can be used. A contract audit is a buyer-initiated audit of prices and other conditions (e.g., terms of delivery, warranty, terms of payment), which aims to increase the fairness of these contracts. ${ }^{1}$ Since World War II, this type of contracting has been increasingly used in defense and space procurement by the U.S. and Western European governments (NATO AC/327, 2007).

Contract audits are usually initiated by organizations that buy through formal written contracts in imperfect markets of goods and services. ${ }^{2}$ As in the defense example, investment selection in these markets cannot be made under competitive conditions - e.g., by public tender - because there are only one or a few suppliers. ${ }^{3}$ This may lead to non-competitive prices and other unfavorable contract conditions. In practice, the contract price is determined by the seller's costs and a profit mark-up. However, without audit, the costs are known only to the seller, who may use this informational advantage to increase the mark-up. Governmental institutions hope that contract audits will help to decrease the negative effects of this moral hazard by enhancing the 'fairness' of the contract prices. ${ }^{4}$

Contract audits can be performed before, during or after the writing of a contract, or even at its termination. The most common contract audit is performed before a contract is written to enhance the fairness of the contract. This is the kind we focus on. Moreover, a contract audit may be statutory or voluntary. In the former case, a government institution is obliged to have an audit undertaken for any major procurement operation. For defense contracting, such a formal requirement for contract auditing in non-competitive markets is established by law in about $50 \%$ of the NATO member countries (NATO AC/327, 2007).

\footnotetext{
${ }^{1}$ The contract audit Manual (CAM) of the US Defense contract audit Agency (DCAA) describes the goals and methods of contract auditing as follows (DCAA (2008) CAM Vol.1, Chapter 1, paragraph 1-104.2): 'The purpose of contract auditing is to assist in achieving prudent contracting by providing those responsible for Government procurement with financial information and advice relating to contractual matters and the effectiveness, efficiency, and economy of contractor's operations. Contract audit activities include providing professional advice on accounting and financial matters to assist in the negotiation, award, administration, re-pricing and settlement of contracts. Audit interest encompasses the totality of contractor's operations. Audits are performed to assure the existence of adequate controls, which will prevent or avoid wasteful, careless and inefficient practices by contractors. These audits include the evaluation of a contractor's policies, procedures, controls and actual performance, identifying and evaluating all activities which contribute to, or have an impact on, proposed or incurred costs of Government contracts.'

${ }^{2}$ Commonly contract audits are conducted before negotiations take place (see below). In this sense, the term 'pre-contract audit' better expresses what is meant. Because the term 'contract audit' is commonly used, we will stick to it.

${ }^{3}$ In addition, the number of buyers in these markets is limited and mostly concerns governmental institutions. We will further discuss this issue, below.
} 
Here, we focus on voluntary audits, where the buyer can choose whether or not to have a contract audit. The audit takes the contract price as the primary audit object. Finally, contract audits are observed in markets where the supply side is imperfect. This means that there is only one or a limited number of sellers. In this paper, we focus on monopolistic markets.

The literature provides little insight into the conditions under which individual decision makers will initiate a voluntary contract audit. Similarly, the effects of contract auditing are little known. ${ }^{5}$ We aim to fill these gaps by using laboratory experiments to identify the factors that explain this decision and to investigate how transaction prices are affected by contract audits. Of course, a buyer may choose to negotiate with the seller without a contract audit. She may ask the seller to supply all information deemed necessary, but is dependent on the seller's good faith to do so honestly and completely. With a high degree of information asymmetry the moral hazard implicit in the relationship potentially leads to overpricing. On the other hand, the buyer is not completely dependent on the seller's whims. For many of the products we are interested in there are usually only a few potential buyers. Negotiations are typically bilateral. If the buyer represents a large nation such as the U.S., this will give her some leverage vis-à-vis the seller. On the other hand, governments of smaller nations will typically have less bargaining power. In our experiments, negotiations will indeed be bilateral, but as in most cases of government procurement sellers will, in the end, have more bargaining power than buyers.

If a buyer decides to have a contract audit undertaken, she starts by giving the assignment to an auditor. The contract auditor will be given access to confidential seller company data, such as price calculations, breakdowns of costs and underlying data. It is therefore necessary that the seller agrees to have an audit performed. After finishing the audit the auditor reports to the potential buyer on the acceptability of the contract price asked by the seller. If this price is not acceptable to the buyer, the auditor will also propose an alternative (lower) price to the buyer. The buyer uses the auditor's advice in subsequent negotiations with the seller. In practice, a contract audit is a market good that comes in various quality levels at distinct prices. The buyer can buy more experienced auditors at higher prices and contract auditors can decide how much time to spend on the audit, depending on how much they are being paid for the job. More experienced auditors and more time spent on auditing both lead to an expected decrease in the asymmetry in the information between buyer and seller.

\footnotetext{
${ }^{4}$ For example, the DCAA in the U.S. lists amongst the goals of an audit: "the accuracy and reasonableness of contractors' cost representations" and "the appropriateness of contractual provisions" (DCAA 2008).

${ }^{5}$ In fact, we could find no relevant academic papers by using Google or Google Scholar.
} 
In essence, a buyer contemplating using a contract audit trades off the expected benefits of reduced asymmetry of information with the costs of the audit. It is important to note, however, that the reduced asymmetry does not necessarily lead to reduced prices. This is especially so for the case we focus on, where the seller is a monopolist and has more bargaining power than the buyer. In this case, the asymmetry of information may not matter at all. Standard economic reasoning implies that the monopolist will demand the price that maximizes expected profits and the buyer will accept it if the benefit she gets from the good is higher than this price. In this case, a contract audit will not provide any information that may influence the price. ${ }^{6}$ Yet, contract audits are often done in practice ${ }^{7}$ and communis opinio is that they reduce transaction prices (DCAA 2008). Hence, explanations for why contract audits are done and what their effects are must go beyond this standard economic reasoning. Psychological factors such as the attitude towards audits and the 'fairness' of a price appear to play important roles. We will discuss such explanations in the following section.

Currently, little is known about the value of contract audits. Similarly, the evidence on the value of financial audits ${ }^{8}$ is also limited, despite a more extensive body of research in this area as initiated by Chow (1982) and elaborated upon from a demand-for-audit perspective by, e.g., Lin Seow (2001) and Collis et al. (2004). One of the reasons for the limited information on the effects of both types of audit is the near impossibility to determine their benefits from field data. A monetary estimate of the total value of improved assurance (through a financial audit) or more competitive price (after a contract audit) is needed to calculate these benefits. This information is typically not available in the field. Laboratory control we use allows us to precisely determine these benefits for the contract audit case. Our conclusions will be limited to a better understanding of contract audits. Similar research could be undertaken to better understand financial audits.

This potential for laboratory experimentation in auditing has been recognized before (e.g., DeJong et al. 1985; DeJong and Forsythe 1992; Wallin 1992; Maines et al. 2006). Closest to our research are Kachelmeier (1991) and Dopuch et al. (1989). Kachelmeier (1991)

\footnotetext{
${ }^{6}$ If there are at least two sellers, Bertrand-type competition may reduce prices to marginal costs, making information asymmetry irrelevant. This assumes, however, that collusion between companies is impossible. We avoid this kind of complications by focusing on the monopoly case.

${ }^{7}$ In a survey on contract audit issues in 24 NATO and Partner countries, about half of the countries indicate that contract audits are performed without a legal obligation to do so (NATO AC/327, 2007).

${ }^{8}$ A financial audit or audit of financial statements is conducted to determine whether the overall financial statements (the quantifiable information being verified) are stated in accordance with specified criteria (Arens and Loebbecke (1994), 4). Another definition of financial audit is the examination by an independent third party of the financial statements of a company or any other legal entity (including governments), resulting in the publication of an independent opinion on whether or not those financial statements are relevant, accurate, complete, and fairly presented (http://en.wikipedia.org/wiki/Financial_audit).
} 
uses experiments to measure the effects of auditing on managerial remuneration for prudent financial reporting. His findings provide empirical support for conclusions that multi-period market mechanisms in combination with auditing can mitigate welfare losses due to information asymmetries. However the exact effects of auditing on managerial remuneration remain equivocal. Dopuch et al. (1989) measure the economic efficiency in experimental markets with and without different credibility mechanisms available to sellers and buyers. Their results show that each of these mechanisms individually increases economic efficiencies reducing moral hazard and adverse selection problems, but maximum efficiency is not achieved. Our paper complements these studies in various ways. First, we investigate a monopolistic market. This mirrors the procurement situation that motivated our research. Second, we aim to use the possibility offered by laboratory control to directly measure the costs and benefits of contract audits in order to better understand their raison-d'être. Finally, we will use our experimental data in combination with behavioral theories to develop a better understanding of why individuals initiate contract audits in the first place.

The remainder of this paper is organized as follows. Section 2 presents a discussion of possible theories explaining the use of contract audits and derives hypotheses. Our experimental procedures and design are described in section 3. Section 4 briefly describes the game theoretical predictions for these parameters. Section 5 presents our results and section 6 concludes.

\section{Theory and Hypotheses}

To develop a framework for understanding contract audits and their consequences, we address the issue from two different angles. On the one hand, we consider the normative aspect of why contract audits may exist by applying the economic theory of organizations, in particular, agency theory and the theory of transaction costs. These theories look upon organizations from a contractual perspective. Though they do not explain why individuals actually choose to have audits done, these theories provide a rationale for their existence. From a more positive perspective, the theory of planned behavior and economic theories of other-regarding behavior will be used to explain why contract audits are undertaken and why they may affect the outcome of negotiations. Together, these theories will allow us to derive a set of hypotheses that we will test with our experimental data.

Though the relationship between buyer and seller is not a standard principal-agent setup (Pratt and Zeckhauser 1985), the information asymmetry between (potential) contract 
partners is very similar and yields transaction costs like any principal-agent relationship. We know from the agency literature that formal contracts cannot solve this asymmetry, but principals typically have several instruments at their disposal to limit and monitor the actions of the agent. Contract auditing may be seen as a form of monitoring that helps to decrease the problems associated with incomplete contracts. From this perspective, their existence may be justified.

Transaction costs theory points to costs needed to complete a transaction that are over and above the direct production costs. Examples of transaction costs related to procurement include the costs of assessing the fairness of offered prices and negotiations over and closing of contracts. The most important sources of transaction costs are bounded rationality and opportunism. Control structures (e.g., competitive markets) provide institutional frameworks within which transaction costs can be minimized (Williamson, 1979). Possible control structures vary from closing deals on a market, negotiating specific contracts between autonomous parties to control transactions and closing transactions within an organization whereby parties lose their autonomy (Williamson, 1985). The goal of transaction cost theory is to determine the control structure that minimizes transaction costs. Contract auditing may be an effective instrument to control the costs of transactions and the closing of contracts, and can be applied when contracts between autonomous parties are negotiated. It may also reduce the costs related to the opportunism of sellers. This would increase the suitability of contract audits as part of a control structure for the case of government procurement on noncompetitive markets. Whether or not contract audits do indeed constitute a suitable element of a control structure for this environment is largely an empirical question. Our experiments provide data allowing us to address this issue. We will see that audits increase the probability that trades take place and reduce the opportunism of sellers. In this respect they do decrease transaction costs.

The contractual perspective thus explains how contract auditing can reduce information asymmetries and transaction costs, serving the goal of prudent contracting (which is central in the DCAA 2008 definition of contract auditing; $c f$. fn. 1). On the other hand, contract auditing is not the only instrument available to achieve prudent contracting. So, the question arises as to why organizations or individuals within these organizations opt for contract auditing? We draw upon the theory of planned behavior to answer this question (Ajzen 1991).

To the best of our knowledge, we are the first to apply the theory of planned behavior in the accounting literature. This theory is originates in psychology. The theory of planned 
behavior postulates three antecedents of the intention, or motivation, to engage in certain behavior, such as initiating a contract audit. The first is the individual's attitude, i.e., her evaluation or appraisal of the behavior. A buyer who believes that the contract will improve if a contract audit is undertaken, clearly has a positive attitude towards the contract audit and hence is more motivated to engage in one. The second antecedent is a subjective norm that represents external (e.g., social) pressures to engage or not to engage in the behavior in question. If society or political superiors put pressure on the buyer to engage in a contract audit, then there is a higher motivation to do so. The third antecedent is the perceived behavioral control. This refers to the perceived ease or difficulty to exhibit certain behavior. A buyer who believes that organizing and executing a contract audit can easily be done at a reasonable price will be more motivated to hire a contract auditor. Obviously, these antecedents are not independent. E.g., one's attitude towards certain behavior may shape one's perception of behavioral control. Similarly, interaction effects may exist between subjective norms with both attitude (e.g., societal or political pressure that influences the attitude toward a contract audit) and perceived behavioral control (e.g., societal or political pressure that influences the perception of the feasibility of a contract audit).

The theory of planned behavior sets out to explain behavior that is germane to specific tasks, circumstances and situations. Hence, an application to contract auditing may reveal more accurate predictions of behavior than a theory that only incorporates more generic personality traits such as abilities and attitudes. However, for the theory of planned behavior to provide accurate predictions, three conditions must be met. First, measures of behavior and the behavior itself must be aligned. Second, ability and motivation must remain stable. Third, perceptions of ability must realistically reflect actual control (Ajzen 1991, p.185). Note that laboratory control allows one to create an environment that closely fulfils these three conditions. For example, (1) we can directly measure choices (i.e., behavior); (2) we can keep the environment constant; and (3) we can create maximum clarity about what an individual can do and what the consequences of distinct choices are. From an empirical perspective, we can add that to test the theory's predictions, one needs to know an individual's attitudes and perceived control as well as the pressures she is subjected to. The laboratory provides an excellent environment to measure and manipulate these as well and will allow for careful testing of the theory of planned behavior's predictions with respect to the individual choice for a contract audit.

Though the theory of planned behavior explains why people choose the instrument, it is not a theory that allows one to understand the net benefits of contract auditing. As stressed 
above, in monopolies sellers can dictate prices, as a result of which there is no direct reason auditing does not affect market power - to change transaction prices based on the results of an audit. Even if the demand side is also monopsonistic, there is no reason to expect an audit to have an effect. This only holds if negotiators are purely self-interested, however. Results from a plethora of recent economic experiments question this assumption. Observed deviations from self-interest have laid the foundation for models of social preferences. Different types of models have been formulated describing distinct deviations from self-interest. These can be categorized as: (i) models of inequity aversion, which assume that people attribute negative utility to earnings-differences across individuals (e.g., Fehr and Schmidt 1999, Bolton and Ockenfels 2000); (ii) models of preferences for efficiency or maximum total surplus (e.g., Charness and Rabin 2002); (iii) reciprocity models where individuals want to reward (punish) (un)kind behavior of others (e.g., Dufwenberg and Kirchsteiger 2004). Social preferences in general and inequity aversion in particular can be important elements in explaining the effect of contract audits on transaction prices. Contract auditing helps to reduce information asymmetry but it may also change the perception of fairness based on the auditor's report of the acceptability of the contract price to the potential buyer. ${ }^{9}$ This can have its effect on transaction prices. In particular, social preference theory suggests that vendors may lower their ask price or buyers may increase their bid prices if a contract audit indicates that the originally suggested contract price is somehow unfair. ${ }^{10}$ If sellers have preferences for efficiency, they may also lower their ask price if they think this increases the probability of an agreement. ${ }^{11}$ Given the assumed overpricing in case of a monopoly without contract audit, the most likely scenario is that the price will decrease as a consequence of fairness considerations.

Now, recall that the theory of planned behavior suggests that organizations may engage in contract auditing even in monopolistic markets. Together, social preference theory and the theory of planned behavior imply that in monopolies where individuals have initial positive attitudes toward contract auditing and subjective norms are imposed to engage in it, audits may be undertaken and lead to lower contract prices as a result of social preferences. In turn, this may reinforce the favorable attitude of buyers toward contract auditing.

\footnotetext{
${ }^{9}$ It is less likely that contract audits will be undertaken because of efficiency concerns. Given the buyers' value for the good , $v$, and the sellers' costs, $c$, the trade surplus is given by $v-c$. The price determines the division of this surplus between buyer and seller. Only if $v>c$ and no trade would take place without contract audit (i.e., a trade surplus equal to zero), whereas a contract audit would lead to a trade (with surplus $v-c>0$ ) would efficiency issues arise.

${ }^{10}$ Sellers may also decrease ask prices if they believe that the buyer is more likely to reject an offer after an audit has given evidence that it is somehow unfair.

${ }^{11}$ Note that if no one trades at a loss, the only source of inefficiency is a missed trade in a situation with positive trade surplus (i.e., a buyer's value that is higher than the seller's cost).
} 
To test this combined model we formulate hypotheses based on each theory separately. Our hypotheses all assume monopolistic conditions. They hold for environments with monopsonistic demand as well as if there are multiple buyers. The null hypotheses are based on standard economic thinking, i.e., the buyer will not initiate a contract audit:

Null Hypothesis $H_{0}$ : Buyers will not initiate contract audits.

Our alternative hypotheses are based on the theories just described. First, based on the theory of planned behavior we formulate the following hypotheses on the antecedents of contract auditing:

Alternative $H_{1 A}$ : As the buyer's attitude toward contract auditing becomes more positive, she will more often initiate a contract audit.

Alternative $H_{l B}$ : As the pressure to initiate a contract audit increases, the buyer will more often initiate a contract audit.

Alternative $H_{l C}$ : If a buyer believes a contract audit is relatively easy to organize, she is more likely to initiate one.

Second, based on social preference theory we formulate the following hypotheses on the effects of contract auditing:

Alternative $\mathrm{H}_{2}$ : Contract audits result in lower prices compared to prices based on negotiations with no contract audit.

Finally, from the purely monetary perspective of the buyer one might question whether a contract audit should be conducted if its costs exceed the price reduction. To measure the net benefits of contract auditing we formulate the additional hypothesis:

Alternative $H_{3}$ : The average price reduction as a result of contract auditing is equal to or higher than its costs.

As a summary, the interrelation between our hypotheses is represented in figure 1 . 


\section{Figure 1: Hypotheses}

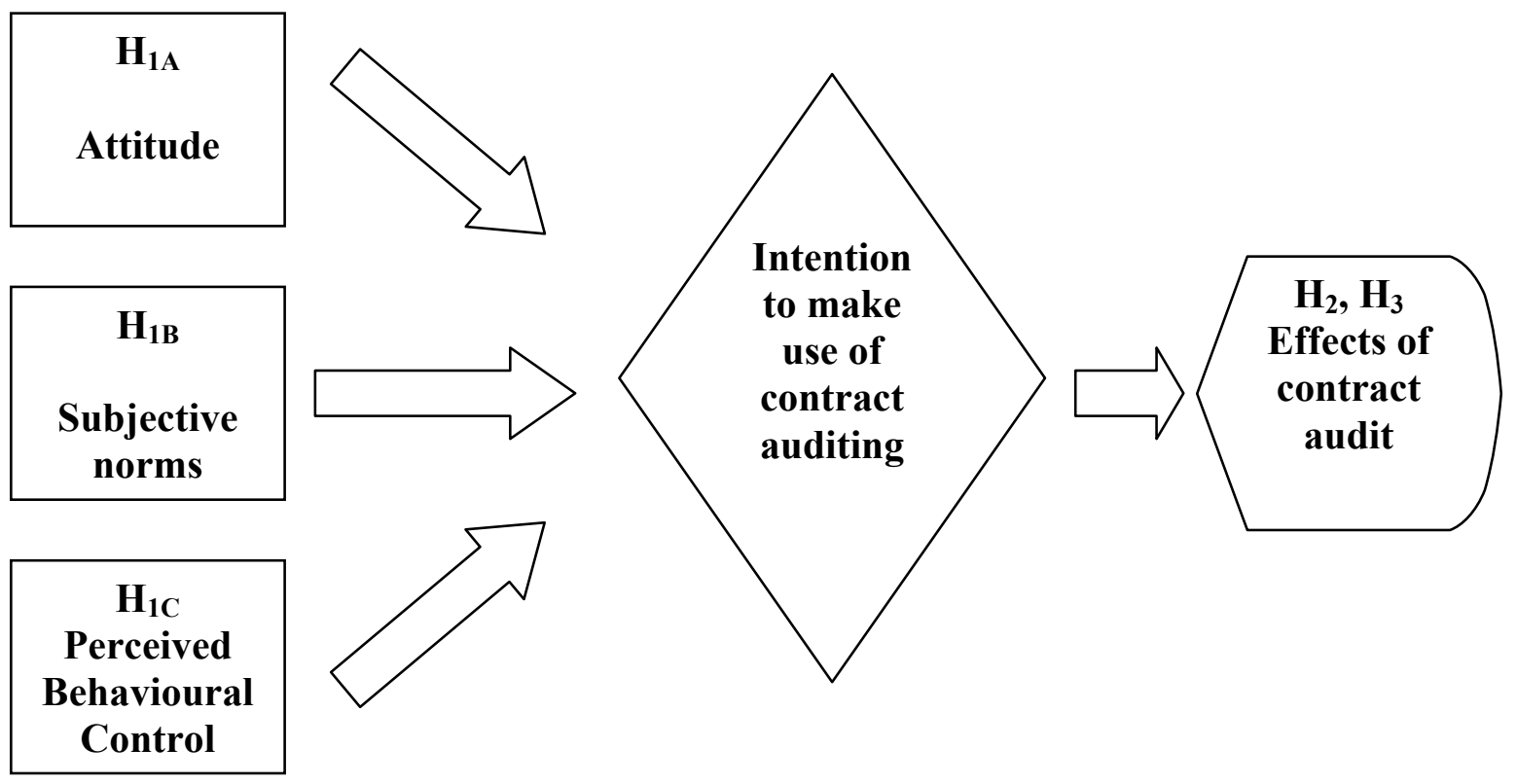

\section{Experimental Procedures and Design}

Ten sessions were run in November 2007 at the laboratory at the Center for Research in Experimental Economics and Political Decision-making (CREED) at the Faculty of Economics and Econometrics of the University of Amsterdam. ${ }^{12}$ The 228 participants were students from the Bachelor and Masters programs at the University of Amsterdam. Each session had 24 participants except the first, which only had 12. Sessions lasted on average about 90 minutes. Participants were paid a show-up fee of $€ 7$ upon arrival and their earnings from the negotiations at the end of the session. Earnings in the experiment are in experimental 'francs', which are exchanged for euros at a rate of $€ 1=10$ francs at the end of the experiment. On average, subjects earned $€ 18.80$, including the show-up fee.

Subjects negotiate in 10 independent periods. Negotiations in the laboratory are bilateral; in every period subjects play a sequential two-person bargaining game with incomplete information, where a buyer and seller negotiate to determine the price of a

\footnotetext{
${ }^{12}$ A translation of the (Dutch) computerized instructions is given in Appendix A.
} 
hypothetical good. ${ }^{13}$ Participants stay in the same role (either buyer or seller) throughout the experiment. To avoid reputation formation and other repeated game effects, subjects are randomly re-matched with new partners at the start of every period. Matches were made within matching groups of six. Hence, a session with 24 participants yields four matching groups. Subjects in distinct matching groups cannot be paired.

If a trade is agreed upon, the seller produces the good at cost $c . c$ is randomly drawn from the set $\{1,2, \ldots, 74,75\}$ (with equal probability for each element) at the beginning of every period and made known only to the seller. The good has value $v$ to the buyer, which is private information. $v$ is randomly drawn (with equal probability) from the set $\{25,26, \ldots, 99,100\}$ at the beginning of every period and made known only to the buyer. All random draws are independent across periods and subjects. If in a period the players agree to trade at price $p$, earnings are $p-c$ for the seller and $v-p$ for the buyer. Accumulated earnings across 10 periods are exchanged for euro's and paid to subjects at the end of the experiment. If a trade is agreed upon, trade surplus is $v-c$. Note that this can vary between -50 and +99 . The a priori probability that a buyer and seller can engage in a mutually beneficial trade (i.e., the probability that $\mathrm{v}>\mathrm{c}$ ) is approximately $78 \%$.

Negotiations are structured as follows. ${ }^{14}$ Each period in the experiment can contain up to three rounds of negotiations. In the first round the seller makes an initial proposal $a_{l}$ (under the restriction that $a_{1} \geq c$ ); the buyer reacts by accepting $a_{1}$ (in which case $p=a_{1}$ ) or by submitting a bid $b_{1}<a_{1}$ (under the restriction that $b_{1} \leq v$ ). In the second round the seller can accept $b_{1}\left(p=b_{1}\right)$ or submit a proposal $a_{2}>b_{1}$ (with $a_{2} \geq c$ ). The buyer reacts by accepting $a_{2}$ ( $p=a_{2}$ ) or by submitting $b_{2}<a_{2}$ (with $b_{2} \leq v$ ). In the third and final round the seller can accept $b_{2}\left(p=b_{2}\right)$ or submit $a_{3}>b_{2}$ (with $\left.a_{3} \geq c\right)$. The buyer then either accepts $\left(p=a_{3}\right)$ or rejects $a_{3}$. This process may or may not result in a completed transaction within three rounds. Note that we attribute relatively strong negotiating power to the seller by giving her the opportunity to make a final take-it-or-leave-it offer. This, once again, reflects the situation in the procurement example motivating this research. Most governments are, in the end, dependent on the firm's final offer.

As a benchmark, we ran 2 sessions (6 matching groups) without contract audits. In all other treatments, the buyer can initiate a contract audit - at a fixed fee of 5 francs - in order to

\footnotetext{
${ }^{13}$ Thus mirrors the situation in the markets for space and defense contracts.

${ }^{14}$ Once again, this design choice is motivated by concerns of external validity. Procurement in the markets that motivate our research typically starts with the buyer allocating a budget for a good or service (represented by $v$ ). The seller is then invited to make an offer. The buyer may accept it or propose an alternative, lower price. Dependent upon various factors, including
} 
acquire information about $c{ }^{15}$ As in real world markets, the option to choose an audit is only available at the start of negotiations, i.e., in the first round, before the seller makes her first offer $a_{l}$. Having an audit conducted changes the buyer's earnings to $v-p-5$, if an agreement is reached. If there is no sale, the buyer still has to pay for the audit, so her earnings are negative for that round $(-5)$. The audit provides the buyer with an estimate, $c_{0}$, of the seller's true costs, $c$. This estimate is a noisy signal with expected value equal to $c$. More specifically, we first determine $c^{*}{ }_{0}=c+\varepsilon$, where $\varepsilon$ is randomly drawn from the set $\{-15,-14, \ldots, 14,15\}$, with equal probability for each element in this set. Then: $c_{0}=c^{*}$, if $1 \leq c^{*}{ }_{0} \leq 75 ; c_{0}=1$, if $c^{*_{0}}<1$ and $c_{0}=75$, if $c^{*_{0}}>75$.

Our first treatment variable intends to vary the pressure put on buyers to have an audit conducted. In government institutions, this pressure typically comes from higher levels of government, stressing the advantages of an audit. Of course, there is no government in the laboratory. In many ways, however, participants may see the experimenter as an authority. In some sessions, we therefore stressed that the experimenter advised the use of contract audits. More specifically, before the start of round 5, the following text appeared on the buyers' monitors: ${ }^{16}$

"As organizers of this experiment, we are in favor of you using an audit. In our experience, this is beneficial for price formation. We therefore advise that you use an audit in every period."

Additionally, before the start of round 8, the following text was sent to buyers:

"We once again point out that we, as organizers of this experiment, are in favor of you having an audit conducted. In our experience, this is beneficial for price formation. We therefore advise that you use an audit in every period." The treatments with messages will be used to test the effect of pressure as formalized in $H_{l B}$.

Our second treatment variable deals with the information sellers have with respect to the contract audit. Sellers always know whether or not an audit is conducted. Whether or not the outcome of the audit is known to the seller before negotiations is varied across sessions. The idea underlying this treatment is that this information may affect the seller's assessment of what the buyer considers to be a 'fair' outcome and may therefore affect the offer the seller

\footnotetext{
technical complexity and risks in developing and producing the requested good or service, one or more iterations are possible. In each iteration, the buyer and seller can accept the price offered by the other party or propose a new price.

${ }^{15}$ We considered making the audit costs dependent on the buyer value, $v$. To aid us in this decision, we collected data from the contract audit department of the Dutch Ministry of Defense about hours spent on specific audits and the corresponding procurement budgets. We found no evidence of such a relation and therefore resort to the more simple case of fixed costs.

${ }^{16}$ Obviously, subjects were not informed that there would be messages. Therefore, rounds 1-4 are identical in treatments with and without messages.
} 
makes. In this way, we may expect $H_{2}$ (that audits yield reduced prices) may be observed more strongly in the treatments where the seller is informed about the audit outcome.

We ran a full $2 \times 2$ design of these two treatments, with 2 sessions ( 8 matching groups) per treatment cell. Table 1 summarizes these treatments with contract audits and gives the acronyms we will use to describe each treatment combination.

Table 1: Treatment Overview

\begin{tabular}{|l|c|c|}
\hline & No Pressure & Pressure \\
\hline Seller not Informed & $n o P / n o I$ & $P / n o I$ \\
\hline Seller Informed & $n o P / I$ & $P / I$ \\
\hline
\end{tabular}

To test hypotheses $H_{1 A}$ and $H_{l C}$, we need information about the buyers' attitudes towards contract audits as well as their perceived behavioral control. We collect this information in a post-experimental questionnaire. ${ }^{17}$ In particular, we used the following two questions. Each of these required a response on a 7-point scale varying from "completely disagree" to "completely agree". 18

Attitude: "By using audits, considerable amounts can be saved on prices paid for goods." Perceived Behavioral Control: "In this experiment, the buyer has a good tool available, which can be used to get information about the seller's costs and a judgment as to how reasonable the seller's ask price is."

Finally, we will test hypotheses $H_{2}$ and $H_{3}$ with data on prices and audit costs as collected in our laboratory sessions.

\section{Benchmark Predictions}

For the parameters in our experiment we can easily characterize the Nash equilibrium in the negotiations, if we assume risk neutrality and payoff-maximizing behavior. Using backward induction, the monopolist will determine the price that maximizes expected payoff in round 3

\footnotetext{
${ }^{17}$ There is, of course, a danger of hind sight bias when applying a questionnaire after the actual decision. In particular, subjects may attempt to justify the use of an audit by responding in the questionnaire that money can be saved and that an audit is a good tool. On the other hand, applying the questionnaire first would raise the danger that subjects may be steered in certain directions by the questions. We consider the danger of hind sight bias to be the lesser of the two.

${ }^{18}$ The complete questionnaire used is available form the authors upon request.
} 
of the negotiations and the buyer will accept any offer that gives her positive earnings. For the final round of negotiations, we therefore have the following equilibrium strategies: ${ }^{19}$

$$
\begin{array}{ll}
\text { Seller: } & \text { choose } a_{3}^{*} \equiv \arg \max _{a} \operatorname{Pr}(a<v) *(a-c)+\operatorname{Pr}(a \geq v) * 0 \\
\text { Buyer: } \quad\left\{\begin{array}{l}
\text { accept } a_{3}^{*} \text { if } v>a_{3}^{*} . \\
\text { reject } a_{3}^{*} \text { if } v \leq a_{3}^{*} .
\end{array}\right.
\end{array}
$$

Knowing equilibrium behavior in the final round, all subgame perfect Nash equilibria consist of seller asking at least $a_{3}^{*}$ in rounds 1 and 2 and the buyer applying the same acceptance rule in all three rounds, while offering any $b_{i} \leq a_{3}^{*}$ if she rejects in rounds $i=1,2$. Finally, there are equilibria where the buyer rejects in round 1 or 2 and offers $b_{i}=a_{3}^{*}$, which is subsequently accepted by the seller. Though this yields a large set of subgame perfect equilibria, the outcome is always the same: there is a trade at price $p=a_{3}^{*}$, if $v>a_{3}^{*}$, and no trade otherwise. Finally, some straightforward calculations yield $a_{3}^{*}=50+\frac{c}{2} \cdot{ }^{20}$ Because prices in the experiment were integer numbers, the equilibrium price is the integer closest to $a_{3}^{*}$. Note that this implies that $p>c$ for any transaction, because $c \leq 75$. This equilibrium holds for all of our treatments, irrespective of the possibility of an audit. In fact, in this equilibrium, buyers will never initiate a costly audit because it will not affect the price.

Note that the equilibrium probability that a trade will take place is decreasing in $c$. For $c=1$, sellers will ask 51 and this will be accepted in 49/76 (64\%) of the cases. For $c=75$, the equilibrium is for sellers to ask 88 , which will be accepted only $12 / 76(16 \%)$ of the time. On average, agreements will be reached in $41 \%$ of the negotiations. Moreover, conditional on an agreement, the expected distribution of surplus always favors the seller. ${ }^{21}$ Hence, the equilibrium may change if preferences are non-selfish, as assumed in social preference theory (e.g., Fehr and Schmidt 1999; Bolton and Ockenfels 2000). In particular, a seller may be willing to reduce the price to share surplus more equally with the buyer. ${ }^{22}$ In fact, maintaining the assumption of risk neutrality, fairness considerations will always lead to lower prices than in the subgame perfect Nash equilibrium based on self-interest. Moreover, if these

\footnotetext{
${ }^{19}$ We assume here that the buyer will reject if indifferent (i.e., the offer is equal to her value), but qualitatively nothing changes if we assume she would accept in this case.

${ }^{20}$ Given the distribution of $v, \operatorname{Pr}(a<v)=(100-a) / 76$. The first derivative of the seller's earnings to $a$ is then $(-2 a+100+c) / 76$.

${ }^{21}$ For the lowest costs, $c=1$, the seller will earn 50 and the average buyer will have $v=75.5$ and earn 24.5. At the other extreme $(c=75)$, the seller earns 13 , the average $v=94$, giving expected buyer earnings of 6 .

${ }^{22}$ Of course, a price reduction by one unit will decrease the seller's earnings by one unit but increase the buyer's expected earnings by less than one, because the buyer's expected value decreases as the set of values larger than the ask price increases by one.
} 
considerations are stronger when the trading partner is aware of the distribution (i.c., this means that the buyer has information about the seller's costs), than a contract audit may lead to a reduction of the price.

\section{Results}

In this section, we first analyze the choice to have contract audits undertaken and test the hypotheses we derived from the theory of planned behavior $\left(H_{1 A}, H_{l B}, H_{l C}\right)$. Then, we study the extent to which agreements are reached and the consequences this has for market efficiency. This is followed by an analysis of the consequences of audits, i.e., the prices and observed distribution of surplus between buyers and sellers. This includes our tests of $\mathrm{H}_{2}$ and $\mathrm{H}_{3}$. In aggregate, we observed 1140 negotiations (38 matching groups, 10 rounds, 3 pairs per round), but the interaction between subjects causes statistical dependencies within these observations. Given that we do not know the structure of the correlations across observations, unless indicated otherwise, we treat the matching group as the independent unit of observation. Hence, each session ${ }^{23}$ provides us with four independent observations for our statistical tests.

\subsection{Contract Audits}

On average, audits were initiated in $44 \%$ of the cases where they were possible. This varied across treatments, however. Figure 2 shows the development of the fraction of audits for the various treatments.

Figure 2: Contract Audits across Periods

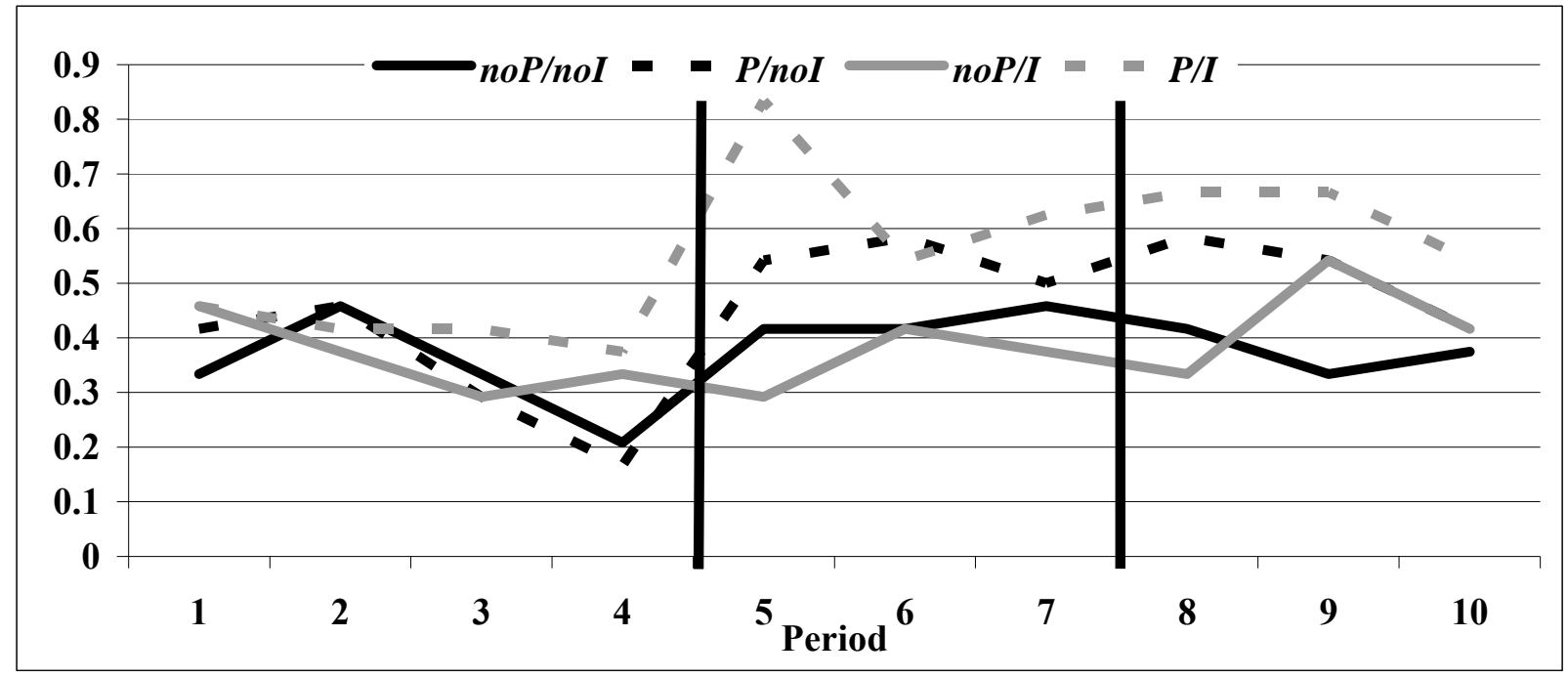

Notes. Lines show across rounds the fraction of negotiations in which contract audits were initiated. Vertical lines indicate

\footnotetext{
${ }^{23}$ An exception is the first session which only had 12 participants (in two matching groups).
} 
the moment in which messages were sent to buyers in the $P / n o I$ and $P / I$ sessions. Treatment acronyms are defined in table 1.

From the figure, it would appear that seller information about the outcome of the audit does not matter much (the differences between noP/noI and noP/I and between $P /$ noI and $P / I$ are small). In fact, differences across treatments appear to be small in the first four periods. On the other hand, the message sent to buyers at the start of periods 5 and 8 does seem to boost the number of audits done. A direct statistical test pertaining to this effect will be presented when discussing the results with respect to our hypotheses, below. Before doing so, we present a multivariate probit analysis aimed at explaining the buyer's decision to ask for a contract audit. Table 2 presents the results. The table's note specifies the regression equation.

Table 2: The Demand for Contract Audits

\begin{tabular}{|l|rl|}
\hline variable & coefficient & z-value \\
\hline constant & -1.343 & $6.83^{* *}$ \\
\hline 1 After Pressure & 0.813 & $4.63^{* *}$ \\
\hline 2 After Pressure & 0.577 & $3.22^{* *}$ \\
\hline 3 After Pressure & 0.433 & $2.32^{*}$ \\
\hline Info to Seller & 0.140 & 0.81 \\
\hline Period & 0.002 & 0.10 \\
\hline Buyer Value & 0.015 & $7.30^{* *}$ \\
\hline
\end{tabular}

Notes. Columns 2 and 3 show the estimated coefficient vector $(\beta)$ and its $z$-value, respectively, of the random effects probit estimation of $P r_{i t}=\Phi\left(\sum_{\mathrm{i}} \mathrm{X}_{\mathrm{it}}^{\prime} \beta+\mu_{\mathrm{j}}\right)$ where $P r_{i t}$ gives the probability that buyer $i$ in matching group $j$ will demand an audit in period $t$. $\Phi$ denotes the cumulative normal distribution and $X$ is the vector of independent variables described in the first column. $\mu_{j}$ is a (white noise) matching-group specific error that corrects for the independence of observations caused by the interaction between individuals within a matching group. The independent variables are defined as follows. 1 After Pressure $=1$ in the period directly following the message projected on the buyer's monitor (i.e., periods 5 and 8) and 0, otherwise. 2 After Pressure $=1$, in the $2^{\text {nd }}$ period after the message (periods 6 and 9) and 0, otherwise. 3 After Pressure $=1$, in the $3^{\text {rd }}$ period after the message (periods 7 and 10) and 0 , otherwise. Info to Seller $=1$, in sessions where sellers know the outcome of the audit and 0, otherwise. Period = number of the period $(\in\{1, \ldots, 10\})$. Buyer Value $=$ realized $v .{ }^{*}=$ statistically significant at the $5 \%$-level; $* *=$ statistically significant at the $1 \%$-level.

The results confirm that the fact that sellers receive information about the outcome of the audit does not affect the buyer's decision to have one done. Moreover, after correcting for other variables, there is no trend across periods. The message broadcast on the buyer's monitor with the experimenter's endorsement of audits has a strong and significant effect. This effect gradually wears down, though, as the coefficient for the period directly following the endorsement is 0.813 whilst it is down to 0.433 two periods later. Finally, a buyer is more likely to ask for an audit, the higher her value $(v)$ for the good is. This may be caused by a 
combination of two effects. On the one hand, the lower $v$ is, the lower the expected surplus will be, and hence the lower the room to negotiate. Buyers with a low value will tend to accept any prices lower than $v$. On the other hand, the expected profit is lower for low $v$, so the costs of an audit will weigh more heavily on the buyer.

In section 3, we derived three hypotheses on the antecedents of contract auditing from the theory of planned behavior. To test $H_{1 A}$ and $H_{1 C}$, we use subjects' responses to the post experimental questionnaire. In the four treatments with audits 96 buyers (50\% of the 192 participants) filled out the questionnaire. Table 3 gives an overview of their responses to the questions concerned and the fractions of subjects who initiated a contract audit. Focusing first on the rows denoted by "Response" we see that for both questions responses are distributed across the full spectrum of the extent of agreement.

Table 3: Questionnaire Responses

\begin{tabular}{|l|l|c|c|c|c|c|c|c|c|}
\hline \multicolumn{2}{|c|}{ Response category: } & $\mathbf{1}$ & $\mathbf{2}$ & $\mathbf{3}$ & $\mathbf{4}$ & $\mathbf{5}$ & $\mathbf{6}$ & $\mathbf{7}$ \\
\hline \multirow{2}{*}{ Attitude } & Response & 0.10 & 0.11 & 0.13 & 0.19 & 0.20 & 0.18 & 0.09 \\
\cline { 2 - 10 } & Audit & 0.22 & 0.27 & 0.34 & 0.37 & 0.60 & 0.49 & 0.72 \\
\hline \multirow{2}{*}{$\begin{array}{l}\text { Perceived } \\
\text { Behavioral Control }\end{array}$} & Response & 0.01 & 0.08 & 0.10 & 0.11 & 0.31 & 0.23 & 0.15 \\
\cline { 2 - 10 }$y$
\end{tabular}

Notes. Attitude is measured by the extent of agreement to the statement: "By using audits, considerable amounts can be saved on prices paid for goods." Perceived Behavioral Control is measured by the extent of agreement to the statement: "In this experiment, the buyer has a good tool available, which can be used to get information about the seller's costs and a judgment as to how reasonable the seller's ask price is." In both cases, responses vary from 1: "completely disagree" to 7: "completely agree". The rows "Response" show the distributions across the seven levels of agreement. The rows "Audit" show the fraction of subjects at each level of agreement that chose to have an audit done.

First consider $H_{1 A}$, which predicts that buyers with a more positive attitude towards contract audits are more likely to initiate them. In table 3, the attitude towards audits increases as we move from left to right. We indeed observe that the fraction of audits increases almost monotonically. This increase is statistically significant (Kruskal-Wallis, $\chi^{2}=26.29$ $(p<0.01)$. Hence, the null hypothesis of no effect is rejected in favor of $H_{1 A}$.

$H_{1 B}$, that government pressure enhances the use of audits is tested by our treatment where messages are sent to the buyers at the start of rounds 5 and 8 . The regressions reported in table 2 provide support for this hypothesis: more audits are requested in the periods following these endorsements. We can also test this hypothesis directly within the treatment with endorsements. Comparing the use of audits in periods 1-4 (i.e., before any message was sent) to that in periods $5-10$, we see the fraction of audits increasing from 0.38 to 0.59 . This 
difference is statistically significant (Wilcoxon signed rank test, $\mathrm{Z}=-2.692, p<0.01$ ). ${ }^{24}$ Once again, the null hypothesis of no effect is rejected in favor of $H_{1 B}$.

Finally, $H_{I C}$ predicts that buyers with a higher perception of control are more likely to request a contract audit. We test this using the data reported in the last two rows of table 3. Again, moving from left to right in the row marked "Response" indicates more agreement, i.c., higher perceived control. We observe that the fraction of audits increases (almost) monotonically from left to right. This effect is statistically significant (Kruskal-Wallis, $\chi^{2}=$ 22.64, $\mathrm{p}<0.01)$ and the null is again rejected in favor of the alternative $H_{I C}$.

By accepting the three hypotheses $H_{1 A}, H_{1 B}$ and $H_{1 C}$ we demonstrate that the antecedents (attitude, subjective norms and perceived behavioral control) affect the decision to have a contract audit done in the way predicted by the theory of planned behavior. This supports application of this theory to decisions to initiate contract audits.

\subsection{Agreements and Efficiency}

The overall percentage of agreements reached was $59.8 \%$. Table 4 gives the fraction of cases in which price agreement was reached per treatment.

Table 4: Agreements across Treatments

\begin{tabular}{|l|c|}
\hline Treatment & agreements \\
\hline 0 & 0.57 \\
noP/noI & 0.58 \\
noP/I & 0.59 \\
$P /$ noI & 0.61 \\
P/I & 0.63 \\
\hline Overall & $\mathbf{0 . 6 0}$ \\
\hline Contract Audit & 0.71 \\
No Contract Audit & $0.53^{+}$ \\
\hline
\end{tabular}

Notes. Numbers present the fraction of cases in which an agreement was reached. Cases above the overall fraction refer to treatments (cf. section 3): $0=$ benchmark session without audits; $\mathrm{P}=$ pressure; $\mathrm{I}=$ audit result known to the seller. Below the overall fraction we show results for trades with and without audit. ${ }^{+} 0.52$ if sessions where contract audits were impossible are excluded.

The table shows that this percentage is slightly higher in the sessions where we endorsed audits in rounds 5 and $8(P / n o I$ and $P / I)$. However, differences between treatments are not significant. The table also shows that agreements are much more frequent after a contract audit has been executed (71\% vs. 52\%). This difference is statistically significant (Wilcoxon

\footnotetext{
${ }^{24}$ This effect is not due to experience. For the sessions without endorsements the fraction of audits increases only slightly, from 0.35 to 0.40 (Wilcoxon signed rank test, $Z=-1.062$, not significant).
} 
signed rank test, $Z=-3.783, p<0.01)$. This may be due to the fact that potential trade surplus is on average higher for trades with an audit: the average difference between value and costs $(v-c)$ is 30.2 in negotiations with audit and 21.1 when no audit is initiated. ${ }^{25}$

Figure 3 shows the development of agreements across periods. It exhibits no clear trend, indicating no development as subjects gain experience. Because the task at hand is not a difficult one per se, we conclude that from the beginning, subjects understand the tasks they are asked to fulfill. Moreover, note that the difference between the fractions of negotiations that lead to agreement with and without audit exists in all periods except the first.

Figure 3: Agreements across Periods

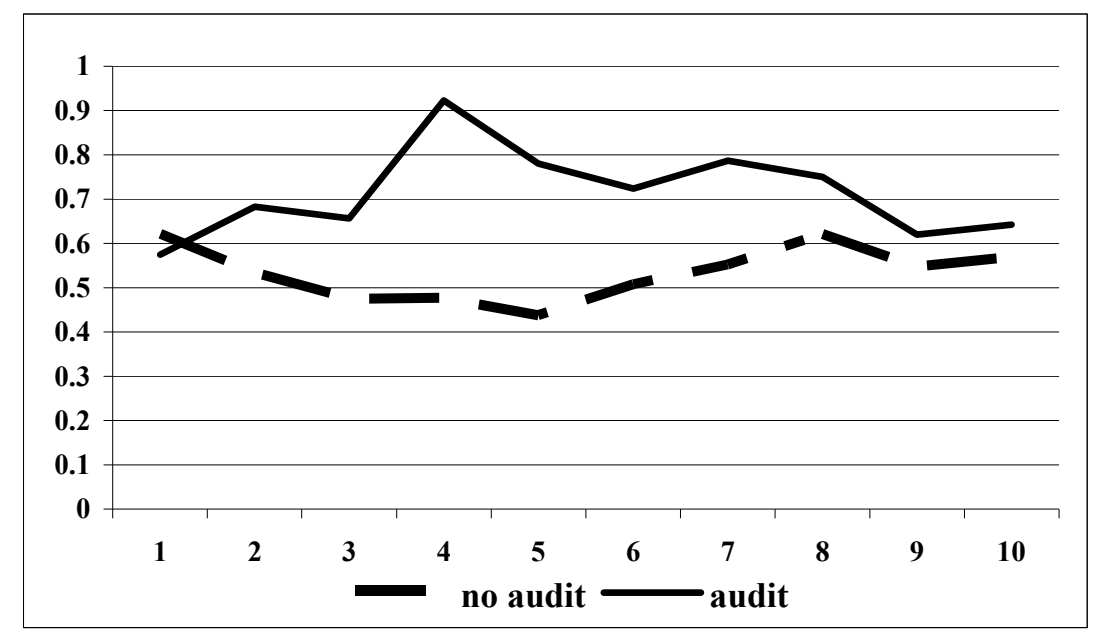

Notes: Lines show fraction of agreements across periods, aggregated across all treatments.

To further study the determinants of reaching an agreement, we ran a random effects probit model explaining their occurrence. Table 5 presents the results, which clearly show that the

Table 5: Agreements

\begin{tabular}{|l|rl|}
\hline variable & coefficient & z-value \\
\hline constant & -1.944 & $8.94^{* *}$ \\
\hline Benchmark & 0.110 & 0.40 \\
\hline After Pressure & 0.040 & 0.26 \\
\hline Info to Seller & -0.142 & 1.16 \\
\hline Period & 0.018 & 0.86 \\
\hline Seller Costs & -0.053 & $16.0^{* *}$ \\
\hline Buyer Value & 0.070 & $18.3^{* *}$ \\
\hline Audit Done & 0.327 & $2.61^{* *}$ \\
\hline
\end{tabular}

Notes. Columns 2 and 3 show the estimated coefficient vector $(\beta)$ and its $z$-value, respectively, of the random effects probit estimation of $P r_{l t}=\Phi\left(\sum_{1} X_{1 t}^{\prime} \beta+\mu_{j}\right)$ where $P r_{i t}$ gives the probability that pair $l$ in matching group $j$ reaches an agreement in period $t$.

\footnotetext{
${ }^{25}$ As we observed in table 2, buyers with high values are more likely to request audits. On average, higher values lead to higher surplus. This may explain the higher surplus when there are audits. We will see below, however, that audits increase the probability of agreement even after correcting for buyers' values and sellers' costs.
} 


\begin{abstract}
$\Phi$ denotes the cumulative normal distribution and $X$ is the vector of independent variables described in the first column. $\mu_{j}$ is a (white noise) matching-group specific error that corrects for the independence of observations caused by the interaction between individuals within a matching group. The independent variables are defined as follows. Benchmark $=1$ when no audits are possible, and 0 , otherwise. After Pressure $=1$, in periods after the message has been projected on the buyer's monitor ( $c f$. section 3 ), and 0 , otherwise. Info to Seller $=1$, in sessions where sellers know the outcome of the audit and 0, otherwise. Period $=$ number of the period $(\in\{1, \ldots, 10\})$. Seller Costs $=$ realized $c$. Buyer Value $=$ realized $v$. Audit Done $=1$ if an audit had been conducted, and 0 , otherwise. ${ }^{*}=$ statistically significant at $5 \%$-level; $* *=$ statistically significant at $1 \%$-level.
\end{abstract}

treatment variables do not affect the probability of an agreement. Both the seller's costs and the buyer's value do, however. As expected, agreement is less likely for higher costs or lower values. Furthermore, even when correcting for costs and values, we observe that agreements are more likely after a contract audit has been done. This may be an indirect consequence of sellers adjusting their ask prices after audits.

The extent to which agreements are reached is the most important determinant of efficiency in this environment. Efficiency basically requires that agreement is reached if and only if $v>c$. Realized surplus without (with) audit is $v-c(-5)$ if a trade is realized and $0(-5)$, otherwise. Table 6 presents realized surplus as a fraction of potential surplus across treatments, distinguishing between trades with and without audit. For the cases with audit, the

Table 6: Efficiency

\begin{tabular}{|l|l|c|c|c|c|c|}
\cline { 3 - 7 } \multicolumn{2}{c|}{} & Benchmark & noP/noI & noP/I & P/noI & P/I \\
\hline \multirow{2}{*}{ No Audit } & 0.91 & 0.88 & 0.82 & 0.89 & 0.89 \\
\hline \multirow{2}{*}{ Audit } & Gross Efficiency & -- & 0.93 & 0.96 & 0.95 & 0.95 \\
\cline { 2 - 7 } & Net Efficiency & -- & 0.83 & 0.85 & 0.84 & 0.85 \\
\hline
\end{tabular}

Notes. Numbers show fraction of potential trade surplus realized. Treatment acronyms are defined in table 1. Gross (Net) Efficiency measures realized surplus before (after) deducting audit costs.

table distinguishes between gross and net efficiency, where the latter deducts audit costs from the realized trade surplus. The table shows that all experimental markets (treatments) are highly efficient. In all cases more than $80 \%$ of possible surplus is realized, in spite of the incomplete information about the other negotiator's costs or value. When an audit is used to alleviate this incompleteness, realized efficiency is always higher, which is a direct consequence of the positive effect that audits have on agreements (together with the fact that subjects almost never trade at a loss). Across all treatments (excluding the benchmark) the difference in efficiency with and without audit is statistically significant (Wilcoxon signed rank test, $\mathrm{Z}=-2.749, p<0.01)$. 
After correcting for the audit costs, audits only improve efficiency in the noP/I treatment. This seems mainly due to the relatively low efficiency of 0.82 when there are no audits. We see no obvious reason for this low efficiency. Neither the number of trades nor the number of audits is exceptional in this treatment. A closer look at the data shows that this is not due to trades with negative surplus (i.e., $c>v$ ), either. What's left is the simple observation that traders for some reason were less able to reach agreement when it was beneficial to both to do so. Finally, across all treatments, the difference between efficiency without audit and net efficiency with audit is statistically insignificant. Considering the difference per treatment, it is only significant for the P/noI case (Wilcoxon signed rank test, Z $=-1.820, p<0.05)$.

\subsection{Price Formation and Surplus Division}

As derived in section 4, traditional economic reasoning assuming self-interested preferences yields a subgame perfect Nash equilibrium where sellers ask a price that increases linearly in their costs: $a_{3}^{*}=50+\frac{c}{2}$. Some of these ask prices will be accepted, others will not, depending on the buyer's value, $v$. Within the set of accepted asks, the equilibrium price is therefore predicted to have the same relationship to costs: $p=50+\frac{c}{2}$. As argued above, prices below this line may indicate social preferences. To start, figure 4 therefore shows a scatterplott showing observed cost-price combinations and their relationship to this line.

Figure 4: Prices vs. Costs

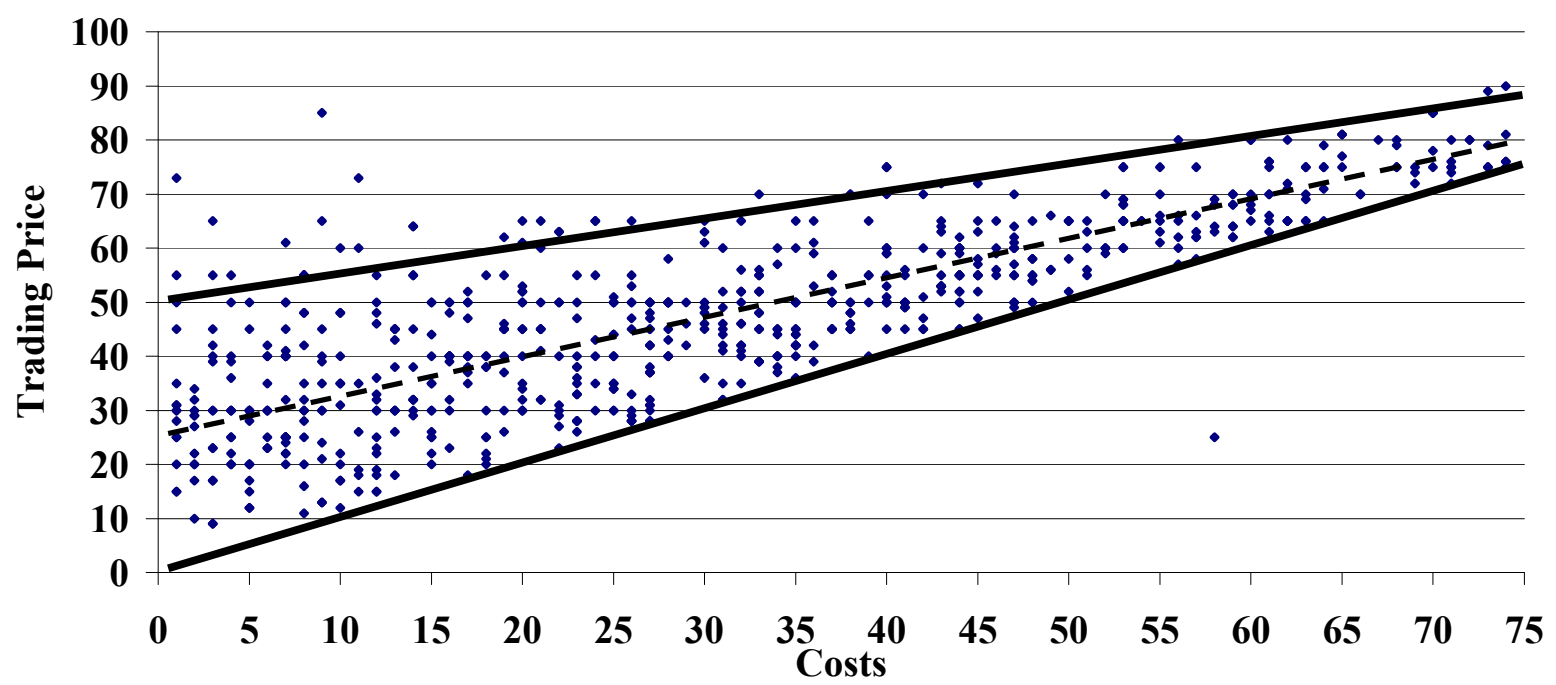

Notes. Dots indicate for all trades the combination of seller's costs and agreed upon price. The lower line indicates the points 
for which $p=c$, i.e., seller earnings are zero. The upper line shows the relationship $p=50+c / 2$ that is predicted by the subgame perfect Nash equilibrium for the negotiations. The dashed line represents the relationship $p=26.81+0.686^{*} c$, which is the random effects OLS relationship estimated from all trades.

It is clear from this figure that almost all transactions are at prices between costs and the Nash prediction. There is only one trade where $c>p .{ }^{26}$ The estimated linear relationship shows that on average sellers are willing to seriously reduce prices compared to the equilibrium based on self-interest. To further investigate the extent to which they are willing to reduce prices, we estimate an index of deviation from the equilibrium, denoted by $\varphi$. Using the cost level as a lower benchmark for this deviation, we define:

$$
\varphi \equiv \frac{a_{3}^{*}-p}{a_{3}^{*}-c}=\frac{50+c / 2-p}{50-c / 2} .
$$

Note that $\varphi>0(<0)$ for prices below (above) the subgame perfect Nash equilibrium for selfinterested sellers $\left(a_{3}^{*}\right)$. Moreover, $\varphi>1(<1)$, for prices below (above) the level of the seller's costs. Hence a value $0<\varphi<1$ indicates a price between costs and the equilibrium. The closer $\varphi$ is to zero, the closer the price is to the equilibrium. Figure 5 shows the average value of $\varphi$ for our treatments.

Figure 5: Average Deviation from Equilibrium

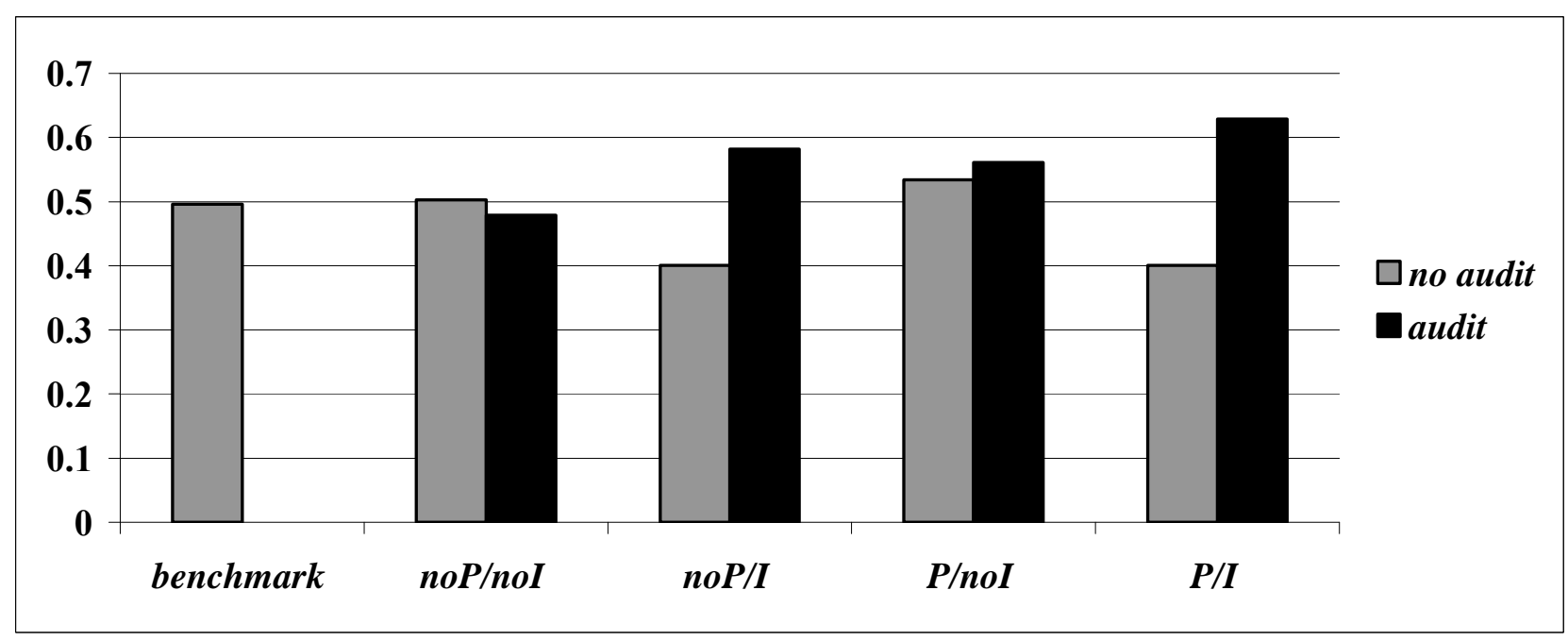

Notes. Bars show the average value of $\varphi$, as defined in eq. (2). Treatment acronyms are defined in table 1.

It appears that in most cases, prices end up about halfway between costs and the equilibrium price. This also holds for the treatments where sellers do not know the outcome of the audit ('noI'), irrespective of whether or not an audit was done. Things change when sellers do know

\footnotetext{
${ }^{26}$ This occurred in the first period of the first session, when a seller accepted a bid below her or his costs.
} 
the outcome of an audit. In both $n o P I$ and $P I$, sellers are willing to move approximately $60 \%$ of the way towards their own cost level if the buyer had an audit conducted. Interestingly, they seem to compensate this in negotiations without audit. In contrast to all other cases, they only deviate from the equilibrium by $40 \%$ when the buyer does not ask for an audit in a situation where the seller would know its outcome. Differences in the mean deviation from equilibrium between the audit and no audit choices (Figure 5) are significant for the noP/I treatment (Wilcoxon signed rank test, $\mathrm{Z}=-2.366, p<0.01$ ) and the $P / I$ treatment (Wilcoxon signed rank test, $\mathrm{Z}=-2.380, p<0.01)$.

The prices at which agreements are reached directly determine the division of surplus between buyer and seller. Obviously, the higher the price is, the lower the buyer's part of trade surplus will be. Denote the buyers share in the surplus of a realized trade at price $p$ by $\theta_{b} \equiv \frac{v-p}{v-c}$, with $0 \leq \theta_{b} \leq 1$ In section 4 we showed that in the equilibrium for self-interested sellers the buyers get less than half of the surplus, i.e., $\theta_{b}<0.5$. Downward deviations from equilibrium will increase the buyer's share, however. Indeed, across all trades, buyers in our experiment manage to appropriate just over $50 \%$ of the surplus, the average value of $\theta_{b}$ is 0.58 . Moreover, the results in figure 5 lead us to expect similar levels of $\theta_{b}$ in the benchmark and in the $n o P / n o I$ and $P / n o I$ treatments. This is indeed what we observe, with the average value varying between 0.50 in the $n o P / n o I$ cases where no audit is done and 0.62 when there is an audit in $P / n o I$. Buyers' success is (as expected from figure 5) more sensitive to audits when the seller knows the outcome. In $n o P / I$, the buyer share is only 0.45 without audit, but is up to 0.64 with audit. When there is also pressure $(P / I), \theta_{b}$ is on average 0.49 without audit. In the majority of these cases an audit is conducted, however, and the buyers manage to obtain more than $2 / 3$ of the surplus: $\theta_{b}=0.69$. All in all, the most effective way of making sellers reduce their prices and thereby increasing the buyers' share in trade surplus is by having contract audits conducted and making the result known to the sellers.

We now turn to the hypotheses we formulated on the effects of contract auditing on prices $\left(\mathrm{H}_{2}\right.$ : contract audits result in lower prices and $H_{3}$ : the average price reduction is equal to or higher than the audit costs). Table 7 gives the average trading price per treatment. Note the difference with the numbers underlying figure 5. In the figure, deviations from equilibrium are depicted, which corrects for differences in costs across treatment. For testing these hypotheses, the prices themselves are more relevant. 
Table 7: Average Prices

\begin{tabular}{|l|c|c|c|c|c|}
\hline & Benchmark & noP/noI & noP/I & P/noI & P/I \\
\hline No Audit & 50.44 & 47.38 & 47.89 & 45.37 & 51.96 \\
\hline Audit & -- & 48.09 & 47.41 & 46.77 & 42.98 \\
\hline
\end{tabular}

Notes. Cell represent average transaction prices for the treatment denoted by the column, distinguishing between trades with and without audit in the rows.

First note that average price differences are small, and across treatment no differences are statistically significant at conventional levels. Within treatments, the difference between trades with and without an audit is only significant for $P / I$ (Wilcoxon signed rank test, $\mathrm{Z}=$ $-2.380, p<0.01)$. Hence, with these tests we can only reject the null of no differences in prices in favor of $H_{2}$, for the treatment where buyers are pressured to use audits and sellers are told the outcome of the audit before the negotiations start. The prices in table 5 are confounded with differences in realized costs and values, however. To obtain a better understanding of the prices agreed upon, we ran a multivariate regression with the price as a dependent variable. To account for censoring at the left by $c$ (sellers will generally not trade at a loss) and at the right by $v$ (buyers will not trade a loss) we use a random effects tobit regression, as specified in the note of table 8 .

Table 8: Price Agreements

\begin{tabular}{|l|rl|}
\hline variable & coefficient & z-value \\
\hline constant & 15.27 & $9.09^{* *}$ \\
\hline Benchmark & -1.407 & 0.80 \\
\hline After Pressure & -0.221 & 0.18 \\
\hline Info to Seller & 1.166 & 1.30 \\
\hline Interaction & -2.665 & 1.61 \\
\hline Period & 0.243 & 1.75 \\
\hline Seller Costs & 0.614 & $29.9^{* *}$ \\
\hline Buyer Value & 0.197 & $9.22^{* *}$ \\
\hline Audit Done & -4.655 & $5.87 *$ \\
\hline
\end{tabular}

Notes. Columns 2 and 3 show the estimated coefficient vector $(\beta)$ and its $z$-value, respectively, of the random effects tobit estimation of $p_{k t}=\sum_{1} \mathrm{X}_{\mathrm{lt}}^{\prime} \beta+\varepsilon_{k t}+\mu_{j}$ where $p_{k t}$ gives the price agreed upon by pair $k$ in matching group $j$, conditional on an agreement being reached, left-censored at costs $c$ and right-censored at value, $v$. $X$ is the vector of independent variables described in the first column. $\varepsilon_{k t}$ is white noise error and $\mu_{j}$ is a (white noise) matching-group specific error that corrects for the independence of observations caused by the interaction between individuals within a matching group. The independent variables are defined as follows. Benchmark $=1$ when no audits are possible, and 0, otherwise. After Pressure $=1$, in periods after the message has been projected on the buyer's monitor ( $c f$. section 3), and 0 , otherwise. Info to Seller $=1$, in sessions where sellers know the outcome of the audit and 0, otherwise. Interaction $=1$ if Info to Seller $=1$ and After Pressure $=1$, and 0, otherwise. Period $=$ number of the period $(\in\{1, \ldots, 10\})$. Seller Costs $=$ realized $c$. Buyer Value $=$ realized $v$. 
Audit Done $=1$ if an audit had been conducted, and 0, otherwise.

$*=$ statistically significant at $5 \%$-level; $* *=$ statistically significant

at $1 \%$-level.

A first thing to note from this table is that the treatment variables themselves have no effect on the price. Information to the seller about the audit only affects prices if the buyer has been pressured to conduct audits, and vice vers $a{ }^{28}$ There is also no trend across periods. Costs and values matter, however. Prices are higher as costs increase and also as values are higher. The latter does not necessarily mean that buyers influence the price in the negotiations, however. Because higher price offers by the sellers are more likely to be accepted by high-value buyers, a positive correlation between prices and values would be expected even if buyers had no chance to negotiate and could only accept or reject the seller's ask price.

Our main concern in table 8 is the effect of audits. The regression results show that after correcting for the other variables, an audit is predicted to decrease the price by 4.7 francs. This effect is statistically significant, providing strong support for $H_{2}$. The effect is less than 5 (the costs of an audit), however. This means a rejection of $H_{3}$ and is an indication that an audit is financially not worthwhile for a buyer.

\section{Discussion}

In this paper we have investigated the reasons why buyers in a situation that mirrors procurement in monopolistic markets choose to initiate a contract audit and have carefully analyzed the effects of the audits. Both the antecedents and consequences of aspects contract audits have thus far been neglected in the literature. With respect to the antecedents, our results confirm three hypotheses that follow directly from the theory of planned behavior. A positive attitude towards audits, perceived behavioral control over audits and (political) pressure to have audits conducted all positively contribute to the probability that an audit will be undertaken. As for the consequences of audits, our results confirm that audits lead to lower transaction prices. For the parameters used in our experiments, the price reduction was insufficient to cover the costs of the audit, however. Finally, we observed that prices tend to be lower than those predicted by the subgame perfect Nash equilibrium of our setup. In fact, without audit, the division of the surplus in trades is close to an equal split.

From an efficiency perspective, audits are desirable because they increase the number of trades with a positive surplus. Of course, some of this surplus is transferred to the auditor,

\footnotetext{
${ }^{28} \mathrm{We}$ conclude this from the high (negative) coefficient for the interaction effect, even though it just misses significance at the $5 \%$-level.
} 
but this is irrelevant if one is only concerned with efficiency. Typically, however, the government's concern in this type of markets will not be efficiency but buyer surplus, because the government is usually the buyer. Though the results with respect to buyer surplus depend on the costs of an audit, our findings indicate that at the very least it is not obvious that the increased buyer surplus will be large enough to cover the audit costs. Further policy recommendations that follow from our findings depend on the desirability of contract audits. If the government has reasons to favor application of audits in this kind of procurement markets, it can stimulate their use by providing information to the government institutions concerned that creates positive attitudes and the perception that audits work. Combined with direct political pressure to apply audits, this will increase their use.

Limitations of this study are germane to any experimental economics approach where markets are simulated in a computer laboratory and where often students are used as decision makers. These problems with external validity need to be weighed against the strong internal validity of laboratory experiments (e.g., the control over costs and values and the possibility to vary treatments one at a time). For a discussion of the trade-off between internal and external validity, see Schram (2005). Here, it suffices to say that our results can serve as a starting point for further experimentation - both in the laboratory and in the field - that will help us to further understand the reason why contract audits are used as well as their consequences when they are indeed used. ${ }^{29}$

\footnotetext{
${ }^{29}$ There are a few obvious candidates for further research in the laboratory. These include testing with various costs and choices between various kinds of audit.
} 


\section{References}

Arens, A.A. and Loebbecke J.K. (1994). Auditing An Integrated Approach. Prentice-Hall International

Ajzen, I. (1991). The Theory of Planned Behaviour. Organizational Behaviour and Human Decision Processes. 50, 179-211

Bolton, G.E. and Ockenfels, A. (2000). ERC: A Theory of Equity, Reciprocity, and Competition, American Economic Review, 90 no.1, 166-193

Charness, G. and Rabin, M. (2002). Understanding Social Preferences with Simple Tests. The Quarterly Journal of Economics. 117, 817-869

Collis, J., Jarvis, R. and Skerratt, L. (2004). The Demand for the Audit in Small Companies in the UK. Accounting and Business Research. 34, no.2, 87-100

DCAA (2008). Defense Contract Audit Agency Contract Audit Manual (CAM), http://www.dcaa.mil/cam.htm

DeJong, D.V., Forsythe, R. and Uecker, W.C. (1985). The Methodology of Laboratory Markets and Its Implications for Agency Research in Accounting and Auditing. Journal of Accounting Research. 23, no.2, 753-793

DeJong, D.V. and Forsythe, R. (1992). A Perspective on the Use of Laboratory Market Experimentation in Auditing Research. The Accounting Review. 67, no.1, 157-170

Dopuch, N., King, R.R. and Wallin, D.E. (1989). The Use of Experimental Markets in Auditing Research: Some Initial Findings. Auditing, A Journal of Practice \& Theory. 8 suppl., $98-127$

Dufwenberg, M. and Kirchsteiger, G. (2004). A theory of sequential reciprocity. Games and Economic Behavior, 47 no.2, 268-298.

Fehr, E. and Schmidt, K.M. (1999). A theory of Fairness, Competition and Cooperation, The Quarterly Journal of Economics, 114 no.3, 817-868

Kachelmeier, S.J. (1991). A Laboratory Market Investigation of the Demand for Strategic Auditing. Auditing, A Journal of Practice \& Theory. 10 suppl., 25-48

Maines, L.A, Salamon, G.L. and Sprinkle, G.B. (2006). An Information Economic Perspective on Experimental Research in Accounting. Behavioral research in accounting. 18, 85-102

Lin Seow, J. (2001). The Demand for the UK Small Company Audit - an Agency Perspective. International Small Business Journal, 19, no.2, 61-79 
NATO AC327 Working Group on Accelerated Fielding, Ad-hoc Working Team on Mutual Provision of Contract Audit. (2007). Report on the assesment of NATO Guidance for mutual provision of contract audits in AACP in view of national differences in contract audit

Pratt, J.W. and Zeckhauser, R.J. (1985). Principals and Agents: an Overview. in: Pratt, J.W. and Zeckhauser, R.J. (Eds.). Principals and agents: The Structure of Business. Boston

Schram, A.J.H.C. (2005). The tension between internal and external validity in economic experiments. Journal of Economic Methodology 12, no.2, 225-237

Wallin, D.E. (1992). Legal Recourse and the Demand for Auditing. The Accounting Review. 67, no.1, 121-147

Williamson, O.E. (1979). Transaction Costs Economics: the Governance of Contractual Relations. Journal of Law and Economics. 22, 3-61

Williamson, O.E. (1985). The Economic Institutions of Capitalism: Firms, Markets, Relational Contracting. New York 


\section{Appendix A: Experimental Instructions}

This appendix gives the English translation of the original Dutch instructions for the sessions with audit where the seller received information about the audit outcome. [Italics in square brackets indicate places where alternative texts were used for the treatment without audit and the treatment where only buyers received the audit information]. The instructions were programmed as html pages. Horizontal lines indicate page separations.

\section{Welcome}

(page 1 of 8 )

You are about to participate in an experiment. The instructions are simple. If you follow them carefully, you may earn a lot of money. Your earnings will be paid to you in euros at the end of the experiment. This will be done confidentially, one participant at a time. In addition, you may keep the 7 euro you received when entering.

In the experiment all calculations are in 'experimental francs'. At the end of the experiment francs will be converted to euros. The exchange rate used is 1 euro for 10 francs.

These instructions cover 8 [no audit treatment: 6] pages like this one. When reading these instructions you may move forward and backward by clicking the mouse on the 'next page' or 'previous page' buttons at the bottom of each page. Sometimes a page will be larger than your screen. In that case you can use the scroll bar and your mouse to read through the entire page.

next page

\section{Rounds and Groups}

(page 2 of 8 )

The experiment consists of 10 rounds.

In each round you will participate in negotiations. These negotiations takes place between one buyer and one seller. The seller offers one unit of an imaginary good for sale. A transaction will take place if the buyer and seller agree on the price. How this adds to your earnings will be explained below.

Only 2 people participate in the negotiations: the buyer and the seller. You will have the same role in all rounds: either buyer, or seller. This will be determined before the start of the first round. The other buyer or seller with whom you will negotiate is always a randomly chosen other participant with that role. This other participant changes every round. However, you don't know who s/he is.

The composition of the negotiating-pairs is anonymous. You don't know who you are dealing with. Others don't know if you are dealing with them.

previous page next page

\section{Buying and selling the good}

(page 3 of 8 )

If the buyer buys the good from the seller, she pays the price they agreed upon. How this price is established will be explained later. 
To produce the good, the seller has to endure costs. These costs will be determined at the start of each round for each seller separately by letting the computer randomly select an integer number between 1 and 75. Each number has the same chance of being selected.

The good is valuable to the buyer because we give it a value. If the buyer buys the good we pay this value. This value will be determined by the computer at the start of each round for each buyer separately. It is a randomly chosen integer number between 25 and 100. Each number has the same chance of being selected.

The costs for the seller and the value to the buyer will be selected independently and will not be disclosed to the other party.

If the buyer and the seller reach an agreement a total surplus can be realised -depending on the costs and value - that can reach a maximum of 99 . The agreed upon price determines the division of this surplus between the buyer and seller. Notice that if the costs are higher than the value, no price exists for which both the buyer and the seller can make a profit. In that case at least one party prefers not to reach an agreement.

If an agreement is reached, the earnings for the buyer are equal to the difference between the value and the agreed upon price. The earnings for the seller are equal to the difference between the agreed upon price and the costs.

Therefore:

Earnings of the seller $=$ agreed upon price - costs.

Earnings of the buyer $=$ value - agreed upon price.

previous page next page

\section{Conducting an audit}

[this page is not included in the treatment without audit] (page 4 of 8 )

Because the buyer has no information about the seller's costs, it is not possible to judge the fairness of the price asked by the seller.

Before negotiations start the buyer is offered the possibility to have an audit conducted to determine the fairness of the price asked. This audit is performed by the computer. Based on the true costs for the seller in the round concerned, the computer gives an estimate of these costs to the buyer. This estimate will also be disclosed to the seller before negotiations start. [in the treatment with only buyer information about the audit this sentence is replaced by: This estimate will not be disclosed to the seller] How this estimate is determined will now be explained.

The estimate of the audit may deviate from the true costs. The estimate can be too high or too low.

To be more precise, the buyer in this experiment can choose between two possibilities at the start of the negotiations;

(1) have no audit conducted. The buyer will get no information about the seller's costs;

(2) have an audit conducted. The buyer receives an estimate of the seller's costs. This estimate is an integer number randomly chosen in the range between the true costs minus 15 francs and the true costs plus 15 francs. Each number in this range has an equal chance of being chosen. 
After the negotiations have started no more audits can be conducted.

previous page next page

\section{Costs of an audit}

[this page is not included in the treatment without audit] (page 5 of 8 )

There are costs related to having an audit conducted. More precisely:

If the choice is to have no audit conducted no costs will be charged.

If the choice is to have an audit conducted 5 francs will be charged on the buyer.

Because the costs of the audit will be subtracted from the earnings of the buyer, it holds for the buyer that:

Earnings of the buyer $=$ value - agreed upon price - costs of the audit.

previous page next page

\section{Negotiations}

(page 6 of 8)

Negotiations take place by alternating bids. The seller has at most 3 chances to ask a price. The buyer has at most 2 possibilities to make a bid.

More precisely, the negotiations proceed as follows:

After the disclosure of the costs to the seller and the value to the buyer and after a possible audit has been performed, the seller opens negotiations by announcing an ask price to the buyer. This ask price has to be larger than or equal to the costs of the seller.

The buyer then has the opportunity to either accept this ask price or make a counter-offer. A counteroffer (offered price) has to be lower than or equal to the value of the buyer and the seller's ask price.

As long as the other's price has not been accepted, the buyer and the seller can make counter-offers. On all occasions the seller's ask price must be higher than or equal to the costs and higher than or equal to the previous price offered by the buyer.

Every price offered by the buyer must be lower than or equal to the value and lower than or equal to the previous price asked by the seller.

If both parties have twice made an unaccepted bid, the seller can make a final bid. The buyer can only accept or reject this final ask price. In case the buyer rejects it there are no earnings for either of them. The buyer does, however, have to pay the costs of the audit if there was one. [this last sentence is dropped in the treatment without audit]

If the buyer or seller accepts the counter-party's price during the negotiations, this is the agreed upon price.

previous page next page 


\section{Information}

(page 7 of 8)

During the negotiations both buyer and seller can see all information about these negotiations on screen.

In this way, the seller sees her or his costs on screen from the start of each round and the buyer sees her or his value on screen from the start of each round. Both the seller and the buyer see the result of a chosen audit. [this last sentence is dropped in the treatment without audit; in the treatment with only buyer information about the audit this sentence is replaced by: The buyer also sees the result of a chosen audit] In addition, information about the stage in which the negotiations are and all prices offered and asked will be shown on screen.

The buyer and seller fill out the input of a new bid in a designated place, after which the 'confirm' button has to be clicked.

After the buyer and seller have finished the negotiations they have to wait until all participants are ready, after which the next round will start.

previous page next page

\section{Finally}

(page 8 of 8 )

This brings you to the end of these instructions. When everybody has finished, we will start the first round of the experiment.

When the first round starts, you can read at the top left part of your screen whether you are a buyer or seller in today's experiment.

If you have finished reading these instructions, you can indicate this by clicking the 'ready' button (at the bottom of this screen). Afterwards please wait patiently until everyone has finished. This may take a little while, so we kindly ask for your patience.

previous page back to the start 